\title{
Laboreal
}

Volume 17 №2 | 2021

Trabalho e Território

\section{0 anos de Médicos sem Fronteiras e os reflexos do trabalho humanitário contemporâneo}

50 años de Médicos sin Fronteras y las reflexiones de la labor humanitaria contemporánea

Quand les 50 ans de Médecins sans Frontières rappelle les évolutions du travail humanitaire contemporain

50 years of Doctors without Borders and the reflections of contemporary humanitarian work

\section{Luciana B. Cavanellas}

\section{(2) OpenEdition}

\section{Journals}

Edição electrónica

URL: https://journals.openedition.org/laboreal/18139

DOI: 10.4000/laboreal. 18139

ISSN: 1646-5237

Editora

Universidade do Porto

Refêrencia eletrónica

Luciana B. Cavanellas, «50 anos de Médicos sem Fronteiras e os reflexos do trabalho humanitário contemporâneo», Laboreal [Online], Volume 17 №2 | 2021, posto online no dia 01 dezembro 2021, consultado o 05 dezembro 2021. URL: http://journals.openedition.org/laboreal/18139 ; DOI: https:// doi.org/10.4000/laboreal.18139

Este documento foi criado de forma automática no dia 5 dezembro 2021.

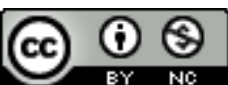

Laboreal está licenciado com uma Licença Creative Commons - Atribuição-NãoComercial 4.0 Internacional. 


\section{0 anos de Médicos sem Fronteiras e os reflexos do trabalho humanitário contemporâneo}

50 años de Médicos sin Fronteras y las reflexiones de la labor humanitaria contemporánea

Quand les 50 ans de Médecins sans Frontières rappelle les évolutions du travail humanitaire contemporain

50 years of Doctors without Borders and the reflections of contemporary

humanitarian work

Luciana B. Cavanellas

\section{NOTA DO EDITOR}

Manuscrito recebido em : 19/09/2021

Aceite após peritagem : 07/10/2021

“A presença aqui de MSF é como uma boia de luz na borrasca” (Dunne, 2012, p. 101)

\section{O nascimento de MSF}

1 A história do movimento humanitário contemporâneo tem como marcos importantes a criação da Cruz Vermelha (1863) e da Convenção de Genebra, em 1864, assinada por 12 potências europeias, inaugurando o chamado direito humanitário internacional.

2 A iniciativa é do filantropo suíço Henri Dunant, cujo livro "Un Souvenir de Solferino" (1862), baseado nas atrocidades da guerra de Lombardie e na agonia de milhares de 
feridos no campo de batalha, propõe a criação de sociedades permanentes de socorro aos feridos (Brauman, 2009).

Mais de cem anos depois, em 1968, um anúncio da Cruz Vermelha, dizendo "Procura-se médicos para Biafra", atrai jovens médicos franceses e dá início a um novo impulso aos movimentos de solidariedade internacional (Aubrée, 2004).

4 A guerra de Biafra, iniciada em 1967, quando declarou-se independente da Nigéria, provocou uma reação militar do governo nigeriano que, além de milhares de mortos, colocou cerca de 8 milhões de biafrenses em situação de fome calamitosa. Segundo Ferré (2007), as imagens da primeira fome televisionada da História chocaram o mundo e evidenciaram a impotência de instituições clássicas como a ONU e a Cruz Vermelha.

5 Dentre os médicos voluntários para a missão em Biafra, seguindo os princípios de neutralidade da Cruz Vermelha, estava Bernard Kouchner, 32 anos, que, inconformado com os horrores testemunhados, decide quebrar o silêncio e cria, junto com outros médicos e jornalistas voluntários, a organização Médicos sem Fronteiras (MSF), em 1971, na França. Com o compromisso de aliar socorro médico e testemunho, em favor das populações em risco, surge com MSF uma "era de médicos franceses que partem para cuidar além das fronteiras e das separações ideológicas" (Aubrée, 2004, p. 13, tradução livre). Denominados "sem fronteiristas", esses médicos, diferentemente de outras ONGs em que atuavam discretamente, pretendem atuar como médicos tanto quanto testemunhas. "Eles ajudam, cuidam e denunciam". Onde quer que haja sofrimento humano, a prioridade é "agir e rápido" (Ferré, 2007, p. 21, tradução livre).

6 Em dezembro de 1971, o jornal médico Tonus anuncia o nascimento de MSF, numa convocação aos médicos:

“(...) votaremos a favor desta mobilização de desejos determinados a derrubar todas as barreiras, todas as fronteiras que ainda existem entre aqueles que têm vocação para salvar, para sangrar, e as vítimas da barbárie humana ou destas perturbações da natureza, das ondas gigantescas, dos terremotos e de outras catástrofes que mergulham no luto os países que muitas vezes estão menos preparados para lidar com elas" (Ferré, 2007, p. 21, tradução livre).

7 Dispostos a romper as fronteiras existentes entre os que têm condições para ajudar e aqueles que precisam de ajuda, o movimento humanitário enfrentará uma série de conflitos e desafios das mais diversas ordens, que o fará confrontar, por vezes, suas próprias convicções.

\section{Expandindo fronteiras}

8 Em 1978, a operação Un bateau pour le Vietnam, apoiada por iniciativa de intelectuais como Jean Paul Sartre e Raymond Aron, e organizada por Bernard Kouchner (Ferré, 2007), com o objetivo de salvar pessoas no mar da China, chamou a atenção da opinião pública para milhares de pessoas que fugiam de seus países em barcos improvisados.

9 Tal operação foi desaprovada por MSF, culminando na saída de Kouchner, que veio a fundar mais tarde a ONG Médicos do Mundo (MDM). Na opinião de Brauman (2003) essa cisão refletiu um momento em que MSF começou a manifestar a necessidade de melhor se estruturar. Diante do enfrentamento de situações inéditas, surgiram no interior de MSF duas correntes distintas: uma que remontava às origens, quando profissionais 
saíam ao terreno com sua "maleta de urgência" e se dedicavam a mobilizar a opinião pública e as organizações com maior poder de intervenção. Outra, para quem tais missões já não bastavam e fazia-se necessário criar uma estrutura própria e independente de atuação. Em 1979, os primeiros, legitimistas, foram vencidos pelos chamados independentistas.

O movimento chamado de French Doctors dominou o cenário humanitário dos anos 80, suscitando vocações e influenciando o surgimento de uma série de associações especializadas em urgências, tais como: ACF (Action contre la faim), ÉQUILIBRE, HI (Handicap International), AMI (Aide médicale internationale). Privilegiando a assistência, mas também baseadas na defesa dos direitos humanos, essas organizações recorreram sistematicamente às mídias para tornar conhecidos dramas humanos os mais longínquos (Ferré, 2007).

\section{A afirmação do "espaço humanitário"}

11 A fome na Etiópia tornou-se um desses acontecimentos emblemáticos, quando em 1984 um jornalista foi autorizado pelas autoridades etiópias a filmar o drama, veiculado pela $\mathrm{BBC}$, que chocou o mundo. O efeito dessa transmissão gerou um dos maiores movimentos de solidariedade na opinião pública mundial. Uma imensa quantidade de suprimentos alimentícios foi enviada à Etiópia, mas as autoridades locais passaram a desviar parte da remessa, colocando-a a serviço de sua política de deslocamento da população (Ferré, 2007). Isso provocou questionamentos e reflexões necessárias ao setor humanitário.

Nesse mesmo contexto, também na Etiópia, deu-se o primeiro enfrentamento entre uma organização humanitária e o Estado em cujo território estava trabalhando. Segundo Brauman (2003), ao protestar contra a utilização dos meios logísticos provenientes da ajuda internacional para o deslocamento forçoso da população, MSF foi expulso do país, diante do silêncio das Nações Unidas e de outras ONGs, que dependiam de financiamentos.

13 A situação da manipulação dos meios de ajuda na Etiópia deixou claro o quão movediço pode ser o terreno humanitário por estar imbricado, em grande parte das vezes, em complexo contexto político. Por tratar-se de um trabalho que ocorre em situações de crise e sofrimento, para além da mobilização de ajuda e tratamento, muitos dilemas acometem a ação humanitária, que se vê diante de decisões difíceis, em um constante debate de normas e valores (Schwartz \& Durrive, 2007).

14 Nem sempre a ajuda é possível porque isso implicaria no silêncio diante de atrocidades testemunhadas. Quando a denúncia e o cuidado às vítimas não são conciliáveis, o que fazer? Como manter os princípios humanitários em face de certas negociações difíceis e necessárias com autoridades locais? Como manter a credibilidade em suas ações e intenções, quando governos se utilizam da imagem construída pelo movimento humanitário para atender seus interesses políticos e econômicos? Para Ferré (2007), as fronteiras já permeáveis entre a política e o humanitarismo se tornaram definitivamente confusas e as missões das ONGs cada vez mais delicadas, por ocorrerem forçosamente no coração da política.

Em 1995, A Cruz Vermelha, juntamente com outras importantes organizações, reafirmou o direito humanitário internacional e o princípio de imparcialidade, segundo 
o qual a assistência deve obedecer à necessidade de aliviar o sofrimento das pessoas. Em 2007, o Consenso Europeu sobre ajuda humanitária convidou as organizações a implementarem suas próprias políticas, independente das políticas governamentais, respeitando os princípios de "humanidade, neutralidade, imparcialidade e independência". Aparece a ideia de "espaço humanitário", tendo a independência como um de seus fundamentos (Coconnier \& Pommier, 2009). A esses quatro, a ONG Médicos sem Fronteiras acrescenta a Transparência e a Ética Médica, reforçando o compromisso com seus doadores e seu papel de prestar assistência médica acima de tudo.

\section{Os riscos da motivação humanitária}

No entanto, apesar da constante reafirmação de seus princípios, a dialética entre segurança e independência permanece e se complexifica ao longo dos anos, no interior do movimento humanitário. Se antes, por volta dos anos 80 e 90, as logomarcas, carros e bandeiras das ONGs significavam garantia de respeito no terreno, atualmente, muitas vezes, opta-se por um certo anonimato e invisibilidade, considerando-se que os mandatos e as bandeiras não garantem mais a proteção dos trabalhadores (Coconnier \& Pommier, 2009).

Entre 2003 e 2007, 88 trabalhadores foram mortos em missão, sendo o pessoal local o mais atingido (Coconnier \& Pommier, 2009). 0 ano de 2006 foi considerado um dos mais violentos, com ataques constantes e o assassinato de 17 profissionais da ONG Ação contra a Fome, no Sri Lanka. Segundo uma pesquisa publicada na época, as estatísticas mostraram que em 10 anos, desde 1997, 408 atos distintos de violência fizeram 947 vítimas das quais 434 mortos. Novamente, os trabalhadores locais foram os mais atingidos (Brauman, 2009). Para citar um fato mais recente relatado no site oficial de MSF [1], em 2020, a maternidade de MSF em Cabul sofreu um ataque brutal a tiros, onde foram mortas 16 mães, 2 crianças e 1 obstetriz de MSF.

Apesar disso e do que as circunstâncias em contextos violentos nos levam a imaginar, a "profissão" humanitária não é considerada estatisticamente mais perigosa quando comparada a muitas outras (Brauman, 2009). Na mesma linha, a exposição aos riscos não parece representar significativamente uma maior dificuldade de recrutamento ou mesmo retenção de trabalhadores no âmbito humanitário. Marcado por uma alta taxa de rotatividade de seus profissionais nas ONGs internacionais, a experiência de atuarem em contextos de alto risco por si só não se mostrou relevante na decisão de aceitarem outra missão (Korff, Balbo, Mills, Heyse, \& Wittek, 2015). Como já o realçamos, "Trabalhadores de MSF têm a liberdade de escolher se aceitam ou não trabalhar em missões que envolvam riscos maiores. E uma vez que concordem, recebem todas as instruções necessárias à minimização dos mesmos; regras da organização visando proteger os profissionais que aceitaram expor-se" (Cavanellas \& Brito, 2019, p. 15).

Movidos por sentimentos de justiça, compaixão e solidariedade, o ingresso em uma ONG como MSF pode significar a realização de um sonho e a confirmação de uma motivação humanitária, considerada fundamental ao enfrentamento das adversidades na missão. 


\section{O campo macropolítico e a experiência no terreno}

No entanto, muitos são os dilemas concernentes ao Humanitário no nível macro, envolvendo decisões importantes acerca das negociações políticas, da capacidade de gestão de conflitos, da mobilização de recursos humanos e técnicos, da preservação da imagem. Há que se considerar ainda temas mais delicados como o direito de ingerência ou o direito de intervir em outro Estado; a sombra da medicina colonial e do neocolonialismo europeu sobre países do terceiro mundo; a utilização do legado (patrimônio adquirido) em favor de interesses escusos e a ajuda que se transforma em indústria. Dificuldades concretas e dilemas éticos relacionados ao campo da ajuda internacional.

21 Mas “a responsabilidade é construída na experiência e no encontro dos sujeitos concretos, na experiência direta de situações vividas por esses sujeitos, fazendo da figura da vulnerabilidade o lugar da incorporação de uma ética da responsabilidade" (Saillant, 2010, p. 63). É no corpo-a-corpo que a atividade humana acontece. Amparados pelas estruturas das organizações, os trabalhadores fazem no terreno, com os pés no chão, sua ação e sua missão. São afetados e transformados pelas circunstâncias e, também, afetam e transformam as pessoas e os lugares por onde passam.

Os desafios dos "sem-fronteiras" são experienciados no campo de relações estabelecidas no terreno, onde é preciso se deixar penetrar pela cultura local, conhecendo e procurando compreender os códigos e valores, dialogando com o verdadeiramente estrangeiro. Cuidar de estrangeiros e trabalhar com o staff local promove exposições a conexões intersubjetivas inéditas, exigindo do expatriado flexibilidade e abertura ao diálogo.

Na atuação humanitária, é preciso substituir o jaleco branco por roupas de um cidadão comum (Brauman, 2003). Afinal, somente no diálogo, onde o diferente tem voz, a compaixão pode dar lugar à solidariedade (Caponi, 2000). Pela importância das vivências dos profissionais na construção da identidade do trabalho humanitário, cada vez mais expostas em diários de bordos e blogs, cabe valorizar não só as macro, mas as micro-intervenções no campo, fazendo migrar o foco de atenção e interesse massivamente voltado às instituições para os indivíduos. Na opinião de pesquisadores como Fechter (2012), os relacionamentos e valores pessoais contribuem significativamente para as perspetivas do trabalho humanitário, sendo fundamental reconhecer os trabalhadores como agentes de mudança, que vivem em meio a uma série de contradições entre vida pessoal e profissional.

A necessidade de construção de uma carreira mais sólida ou de uma vida afetivo-sexual mais estável, além do desgaste físico-emocional imposto pelo trabalho no terreno, representam boa parte das demandas pessoais no trabalho humanitário (Cavanellas \& Brito, 2019), sendo fundamental que o engajamento no cuidado com o outro seja complementado pelo compromisso no cuidado de si (Fechter, 2012). Apesar da mística altruísta e do heroísmo associado à ação humanitária, a atividade acontece no real do trabalho (Lancman \& Sznelwar, 2008) e se baseia efetivamente no propósito de socorrer, em momentos críticos, seres humanos, apoiando-os e ajudando-os a recuperar-se para poderem retomar seu caminho (Brauman, 2003). 


\section{A força da solidariedade}

Com escritórios em 28 países e atuação em mais de 70, Médicos sem Fronteiras representa uma capacidade de prestar cuidados de saúde em uma escala internacional abrangente, graças a operações colaborativas entre suas diferentes associações. Com mais de 45 mil profissionais de diferentes áreas e nacionalidades, entre expatriados e staff local, e tendo $96 \%$ de seu financiamento provenientes de doações individuais e da iniciativa privada, MSF completa 50 anos, com um Prêmio Nobel da Paz em sua história e como um dos símbolos mais eloquentes do movimento humanitário contemporâneo.

\section{BIBLIOGRAFIA}

Aubrée, C. (2004). Les métiers de l'humanitaire et de la solidarité. Paris: L'Etudiant.

Brauman, R. (2003). Humanitario el dilema. Barcelona: Icaria.

Brauman, R. (2009). La Médecine humanitaire. Paris: PUF.

Caponi, S. (2000). Da compaixão à solidariedade. Rio de Janeiro: Editora Fiocruz.

Cavanellas, L. B., \& Brito, J. (2019). Os desafios do cuidado em situações-limite: as dramáticas da atividade no trabalho humanitário. Laboreal, 15(2), 1-26. https://doi.org/10.4000/laboreal.14966

Coconnier, M-L., \& Pommier, B. (2009). L'Action Humanitaire. Paris: PUF.

Lancman, S., \& Sznelwar, L. (2008). Christophe Dejours: da psicopatologia à psicodinâmica do trabalho. Rio de Janeiro: Ed. Fiocruz.

Dunne, C. (2012). Khayelitsha, cidade do Cabo. In M. Llosa, E. Brum, P. Giordano, C. Dunne, A. Barlett, J. Levine, E. Aykel, T. Doshi, \& W. N`Sondé (Eds.), Dignidade! (pp. 71-114). São Paulo: Leya.

Fechter, A-M. (2012). The Personal and the Professional: Aid workers' relationships and values in the development process. Third World Quarterly, 33(8), 1387-1404. https://doi.org/

10.1080/01436597.2012.698104

Ferré, J-L. (2007). L'action humanitaire. Toulouse: Milan.

Korff, V., Balbo, N., Mills, M., Heyse, L., \& Wittek, R. (2015). The impact of humanitarian context conditions and individual characteristics on aid worker retention. Disasters, 39(3), 522-545. https://doi.org/10.1111/disa.12119

Saillant, F. (2010). A Responsabilidade na intervenção humanitária: indiferença ou engajamento? In J. Ferreira, \& P. Schuch (Orgs.), Direitos e ajuda humanitária: perspectivas sobre família, gênero e saúde (pp. 49-75). Rio de Janeiro: Editora Fiocruz.

Schwartz, Y., \& Durrive, L. (2007). Trabalho e Ergologia, conversas sobre a atividade humana. Niterói: EDUFF. 


\section{NOTAS}

1. Recuperado em 06 de setembro de 2021, de https://www.msf.org.br/nossa-historia

\section{RESUMOS}

A ONG internacional Médicos sem Fronteiras (MSF) faz 50 anos em dezembro de 2021. A sua história e ação revelam eventos importantes e necessários à compreensão do movimento humanitário contemporâneo. Das negociações em contextos políticos complexos às vivências pessoais de trabalhadores que se arriscam para prestar ajuda e solidariedade, os conflitos e dilemas são constantes quando se trata de conciliar medicina e testemunho do sofrimento humano. Para fundamentar e enriquecer a reflexão, este texto procura apresentar contribuições de estudiosos e protagonistas do trabalho humanitário, dispostos a mostrar as dificuldades enfrentadas e as contradições a serem superadas. Com mais de 45 mil profissionais, atuando em mais de 70 países, MSF segue preservando seus princípios, desafiando fronteiras e buscando levar cuidado a quem precisa.

La ONG internacional Médicos Sin Fronteras (MSF) cumple 50 años en diciembre de 2021. Su historia y sus acciones revelan acontecimientos importantes que son necesarios para comprender el movimiento humanitario contemporáneo. Desde las negociaciones en contextos políticos complejos hasta las experiencias personales de los trabajadores que se arriesgan para prestar ayuda y solidaridad, los conflictos y dilemas son constantes cuando se trata de conciliar la medicina y ser testigo del sufrimiento humano. Para fundamentar y enriquecer esta reflexión, este texto pretende presentar las aportaciones de los estudiosos y protagonistas de la labor humanitária, dispuestos a mostrar las dificultades a las que se enfrentan y las contradicciones que hay que superar. Con más de 45 mil profesionales, trabajando en más de 70 países, MSF sigue preservando sus principios, desafiando las fronteras y tratando de llevar atención a los necesitados.

L'ONG internationale Médecins Sans Frontières (MSF) complète 50 ans en décembre 2021. Son histoire et ses actions révèlent des événements importants qui sont nécessaires pour comprendre le mouvement humanitaire contemporain. Qu'il s'agisse de négociations dans des contextes politiques complexes ou de l'expérience personnelle des travailleurs qui prennent des risques pour apporter aide et solidarité, les conflits et les dilemmes sont constants lorsqu'il s'agit de concilier médecine et témoignage de la souffrance humaine. Pour fonder et enrichir cette réflexion, ce texte cherche à présenter des contributions de chercheurs et de protagonistes du travail humanitaire, désireux de montrer les difficultés rencontrées et les contradictions à surmonter. Avec plus de 45.000 professionnels, travaillant dans plus de 70 pays, MSF continue à préserver ses principes, à défier les frontières et à chercher à apporter des soins à ceux qui en ont besoin.

The international NGO Doctors Without Borders (DWB) turns 50 years old in December 2021. Its history and actions reveal important events that are necessary to understand the contemporary humanitarian movement. From negotiations in complex political contexts to the personal experiences of workers who risk themselves to provide aid and solidarity, the conflicts and dilemmas are constant when it comes to reconciling medicine and witnessing human suffering. 
To ground and enrich the reflection, this text seeks to present contributions from scholars and protagonists of humanitarian work, willing to show the difficulties faced and the contradictions to be overcome. With more than 45 thousand professionals, working in over 70 countries, MSF continues to preserve its principles, challenging borders and seeking to bring care to those in need.

\section{ÍNDICE}

Keywords: humanitarian movement, doctors without borders, care, witness, solidarity Palavras-chave: movimento humanitário, médicos sem fronteiras, cuidado, testemunho, solidariedade

Palabras claves: movimiento humanitario, médicos sin fronteras, atención, testigo, solidaridad

Mots-clés: mouvement humanitaire, médecins sans frontières, soins, témoignage, solidarité

\section{AUTOR}

\section{LUCIANA B. CAVANELLAS}

https://orcid.org/0000-0003-0562-6507

Fundação Oswaldo Cruz, Coordenação de Saúde do Trabalhador (CST/Cogepe/Fiocruz)

Avenida Brasil, 4365. Pavilhão Carlos Augusto da Silva. Manguinhos, Rio de Janeiro, Brasil, 21040-36

luciana.cavanellas@fiocruz.br 